\title{
The Effects of The Ingredients of Kuntai Capsules on LIF and PCNA Protein Expressions in Perimenopausal Mice
}

\author{
Qiliang Zhou ${ }^{1 *}$, Youru Zhou ${ }^{2}$, Zhihuo Liu ${ }^{1}$ \\ ${ }^{1}$ Human Department of Anatomy and Embryology, Changsha Medical \\ University, Changsha, Hunan 410219, P.R. China; \\ ${ }^{2}$ Undergraduate in the Department of Clinical Medicine, Changsha Medical \\ University, Changsha, Hunan 410219, P.R. China. zy199500@qq.com.
}

*Correspondence: Qiliang Zhou, Professor, Changsha Medical University. Email: 1223796992@qq.com.

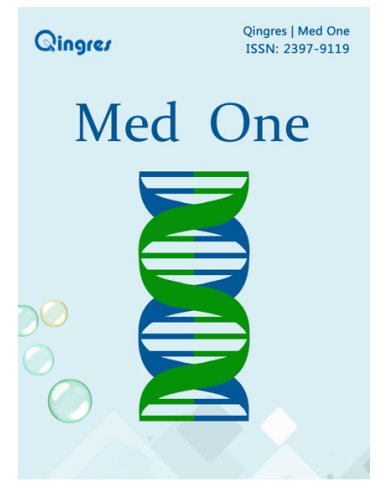

http://mo.qingres.com

\section{GOPEN ACCESS}

DOI: 10.20900/mo.20170009

Received: January 25, 2017

Accepted: March 20, 2017

Published: April 25, 2017

Copyright: $\odot 2017$ Cain et al. This is an open access article distributed under the terms of the Creative Commons Attribution License, which permits unrestricted use, distribution, and reproduction in any medium, provided the original author and source are credited.

\begin{abstract}
Objective: Evaluate the efficacy of the contents of Kuntai capsules (a Chinese patent medication) by observing the effects on leukemia inhibitory factor (LIF); proliferating cell nuclear antigenting (PCNA) expressions; and endometrial thickness, to better understand the multiple functions of LIF and PCNA proteins and provide an experimental basis for clinical use.
\end{abstract}

Methods: Twenty procreated Kunming female mice (8-10 months old) and five childless Kunming mice ( 8 weeks old) were selected. Grouping: twenty adult mice were divided into a three groups by drug concentration (high, medium, and low ) and a control group via a randomized block method. The five childless mice were the young group. The mice in drug groups were fed Kuntai capsules in daily dosages of $180 \mathrm{mg} / 100 \mathrm{~g}$ (high), $90 \mathrm{mg} / 100 \mathrm{~g}$ (medium), and 45 $\mathrm{mg} / 100 \mathrm{~g}$ (low), once a day for successive nine days. The mice in control group and the young group were provided equal volumes of distilled water every day.

Results: The protein expressions of PCNA and LIF protein in adult female mice decreased compared to young female mice.

Conclusion: The contents of Kuntai capsules may significantly ameliorate perimenopausal endometrium-caused negative effects. Mice of all ages were normal, and the protein expressions of LIF and PCNA in mice in the groups differed significantly.

Key Words: Kuntai capsule; perimenopausal period; LIF; PCNA 


\section{INTRODUCTION}

Recent studies ${ }^{[1,2]}$ have shown that LIF and PCNA proteins expressing in the uterus play an important role in improving pregnancy rates. Most studies have focused on those of child-bearing and childrearing ages who are unable to become pregnant normally. The studies have not tested older women who are preparing for second children after the implementation of the two-child policy in China. Kuntai capsules, a Chinese patented medication, have been widely-used in treating menopause ${ }^{[3]}$. In this experiment, Kuntai capsules were administered during older women's preparation for pregnancy in order to explore their function in improving intrauterine conception environment in addition to any treatment efficacy on the menopausal symptoms so as to provide a theoretical basis for clinical use.

\section{MATERIALS}

\subsection{Laboratory Apparatus}

\begin{tabular}{lll}
\hline Name & Manufacturer & Art. No. \\
\hline Shaker & Kylin-bell & TS-92 \\
Incubator & Beijing Liuyi Instrument & DYY-6C \\
Microwave oven & Midea & MM721AAU-PW \\
Slicing knife & Leica & M199 \\
Slicer & Zhejiang Jinhua Yidi Medical Appliance Co., Ltd & YD-315 \\
Embedding machine & Changzhou Zhongwei Electronic Instrument Co., Ltd & BMJ-A \\
Ordinary refrigerator & Royalstar & BCD-245F \\
Precision PH meter & Rex & E-201-C \\
Microscope & Motic & BA210T \\
Cover glass & Haimen Yuantai Labware Co., Ltd & DY89-1 \\
Glass slide & Haimen Yuantai Labware Co., Ltd & AY89-2 \\
\hline
\end{tabular}

\subsection{Main experimental reagents}

\begin{tabular}{ll}
\hline Name of Reagent & Company \\
\hline Conventional chemical reagents & Sinopharm Bio-pharmaceutical Co., Ltd \\
Paraffin & Sigma \\
Neutral balsam & Sigma \\
Brasilin & Wellbio \\
PBS (7.2-7.6) & Wellbio \\
Citrate agar solution (CAS) & Wellbio \\
Two-step method kit & Zhongshan Goldbridge Biology \\
DAB kit & Zhongshan Goldbridge Biology \\
\hline
\end{tabular}




\subsection{Experimental animals}

Kunming (KM) female mice, 8-10 months old, weighing 45-65 g, (animal certificate 43004700021688) and KM female mice, 2-3 months old, weighing $35-40 \mathrm{~g}$, (animal certificate 43004700021689) were used. The mice were provided by the Hunan SLAC Laboratory Animal Co., Ltd, under permit No. SCXK (Hunan) 2011-0003.

\section{METHODS}

\subsection{Modeling}

Twenty procreated KM female mice (8-10 months old) and five childless KM mice (8 weeks old) were selected. The twenty adult mice were divided into three drug concentration level groups (high, medium, and low) and a control group via a completely randomized block method. Five childless mice were set as the young group. The mice in drug groups were fed Kuntai capsules with a daily dosage of $180 \mathrm{mg} / 100 \mathrm{~g}, 90 \mathrm{mg} / 100 \mathrm{~g}$, and $45 \mathrm{mg} / 100 \mathrm{~g}$, respectively, once a day, for successive nine days. The mice in control group and the young group were provided with an equal volume of distilled water every day. They were killed an hour after the last administration. They were then laparotomized and their uteri removed. The uteri were saline washed and fixed in a $10 \%$ formaldehyde solution and stored in the refrigerator at $4^{\circ} \mathrm{C}$.

\subsection{Specimen Preparation}

Fixation: The female mice uteri were fixed in a $10 \%$ formaldehyde solution for 24 hours.

Dehydration: The fixed uteri were washed in tap water and dehydrated using an alcohol gradient method: 30 minutes in $70 \%$ alcohol; 30 minutes in $80 \%$ alcohol; 30 minutes in $90 \%$ alcohol; and, 30 minutes in $100 \%$ alcohol.

Transparency: Post-dehydration, the uteri were placed in a mixture (ratio 1:1) of xylene and $100 \%$ alcohol for 30 minutes; then in xylene-I for 30 minutes; and, finally in xylene-Il for 30 minutes until the tissues were transparent.

Paraffining: The transparent uteri tissues were placed in a paraffin cup I for an hour; paraffin cup II for an hour, and paraffin cup III for an hour. The entire process finished in the paraffin melter at a maintained temperature of $57^{\circ} \mathrm{C}$.

Embedding: The paraffined uterine tissues were placed in a cassette and marked, and then embedded with the melted paraffin. The paraffin blocks were then decanted after the paraffin solidified.

\subsection{Immunohistochemistry}

1) The slices were baked for $30-60 \mathrm{~min}$ at $60^{\circ} \mathrm{C}$;

2) Slice dewaxing: The slices were twice placed into xylene for $10 \mathrm{~min}$. They were then, for $5 \mathrm{~min}$ each, placed into a $100 \%$ ethanol solution, a $95 \%$ ethanol solution, an $85 \%$ ethanol solution, and a $75 \%$ ethanol solution. Finally, they were immersed in distilled water for $5 \mathrm{~min}$;

3) Heat repair antigen: The slices were immersed into a $0.01 \mathrm{M}$ citrate buffer ( $\mathrm{pH} 6.0)$, and an electric furnace, or microwave oven, heated them to boiling and stopped. The heating was repeated for 6 times after an $8 \mathrm{~min}$. interval. After cooling, they were washed three times in 0.01 M PBS ( $\mathrm{pH}$ 7.2-7.6) for 3 $\min$;

4) They were then dropped in a $3 \% \mathrm{H} 2 \mathrm{O} 2$ for 10 min at room temperature to inactivate endogenous enzymes and then washed three times in PBS for 3 $\min$;

5) Primary antibody incubation: They were dropped in an appropriately-diluted primary antibody (PCNA, LIF), and kept overnight at $4^{\circ} \mathrm{C}$. They were then washed three times in PBS for 5 min;

6) Secondary antibody incubation: They were dropped in 50-100 $\mu \mathrm{L}$ anti-rabbit, rabbit IgG antibody - HRP polymer, incubated for $30 \mathrm{~min}$ at $37^{\circ} \mathrm{C}$ and washed three in PBS for 5 min;

7) DAB developing: They were dropped into a prepared $\mathrm{DAB}$ developer working solution of 50 $100 \mu \mathrm{L}$, incubated for $1-5 \mathrm{~min}$ at room temperature to control the reaction time in a microscope and washed in distilled water;

8) They were then redyed in hematoxylin for 5-10 min, washed in distilled water, and returned to blue in PBS;

9) They were then dehydrate in alcohol at various levels (60-100 \%) for $5 \mathrm{~min}$ at each level. Upon removal from the alcohol they were twice, for 10 minutes, placed in a xylene solution. The slices were sealed in neutral balsam, and observed microscopically.

\subsection{Data analysis}

An ordinary computer was used to sample the images. 
IPP (Image-Pro-Plus) software was used to analyze the images.

Notes: The average IOD was the ratio between the cumulative optical density of positive expression site and the area of the sample under the visual field (for cyclogram of 400 times); The general average IOD was a positive analysis for the non-pure nuclear expression indicator; The positive rate was the ratio between the number of positive expression cell nuclei and total number of cell nuclei under the visual field (for cyclogram of 400 times); and The general positive rate is the positive analysis of pure nuclear expression indicator.

\subsection{Indicator-related experimental conditions}

\begin{tabular}{llcccc}
\hline $\begin{array}{l}\text { Indicator } \\
\text { Name }\end{array}$ & Brand & $\begin{array}{c}\text { Primary antibody art. } \\
\text { No. }\end{array}$ & $\begin{array}{c}\text { Primary antibody } \\
\text { source }\end{array}$ & $\begin{array}{c}\text { Dilution } \\
\text { proportion }\end{array}$ & Expression site \\
\hline PCNA & Proteintech & 10205-2-AP & Rabbit & $1: 200$ & Nuclear, pulp \\
LIF & Proteintech & $26757-1 \mathrm{AP}$ & Rabbit & $1: 100$ & Secretary proteins \\
\hline
\end{tabular}

\section{EXPERIMENTAL RESULTS}

\subsection{Expression of PCNA Proteins by Group}

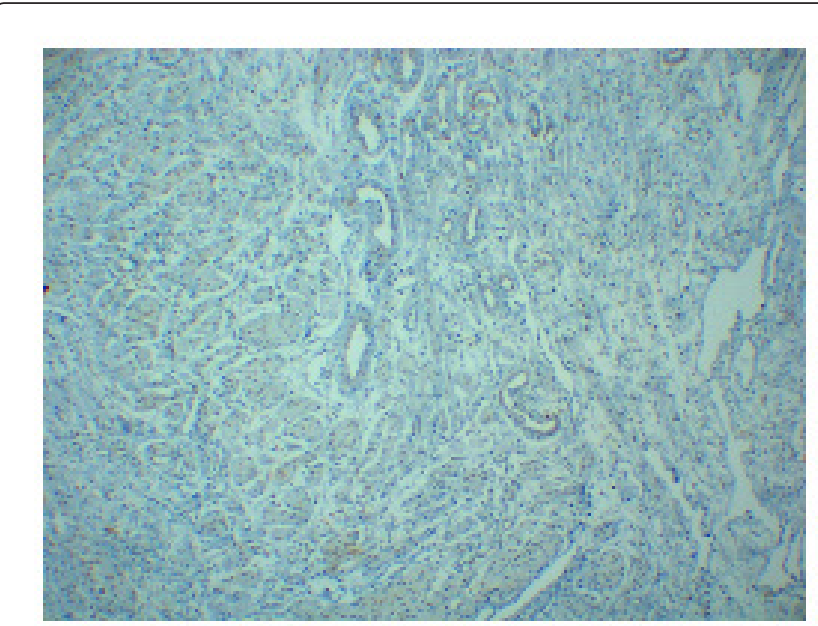

$10 *$

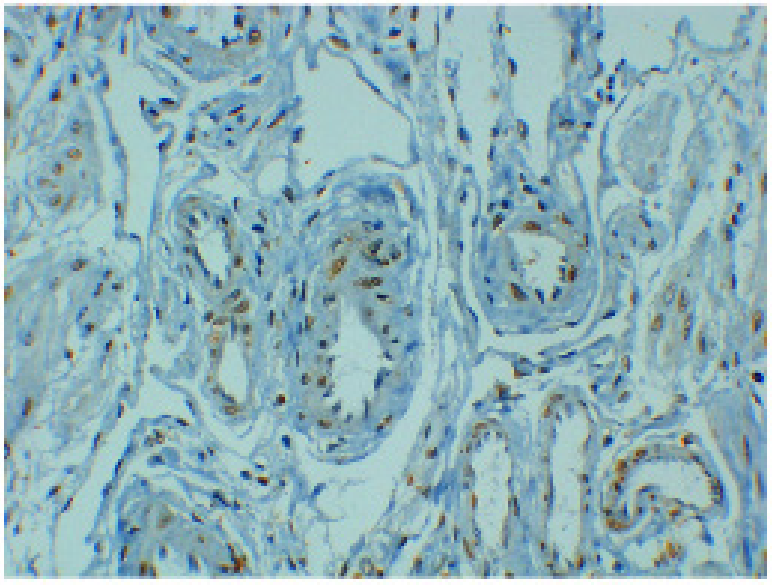

$40^{*}$

\section{A Control}




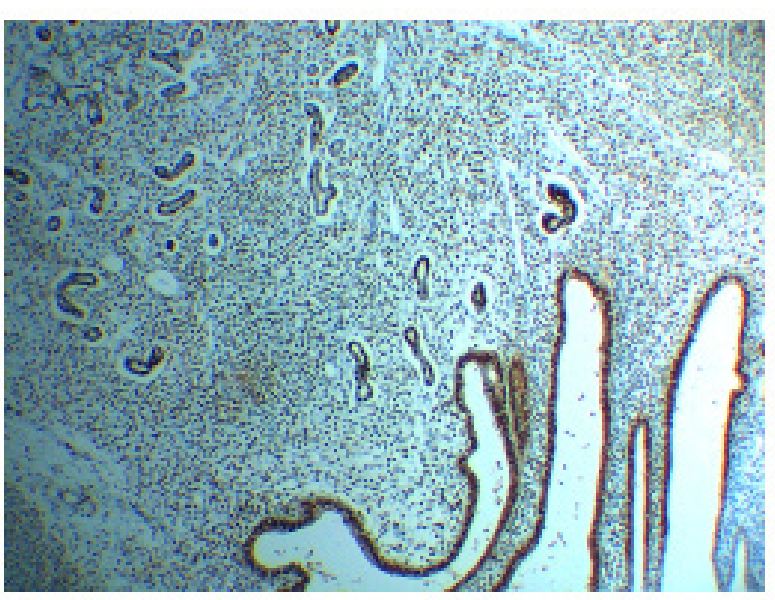

$10^{*}$

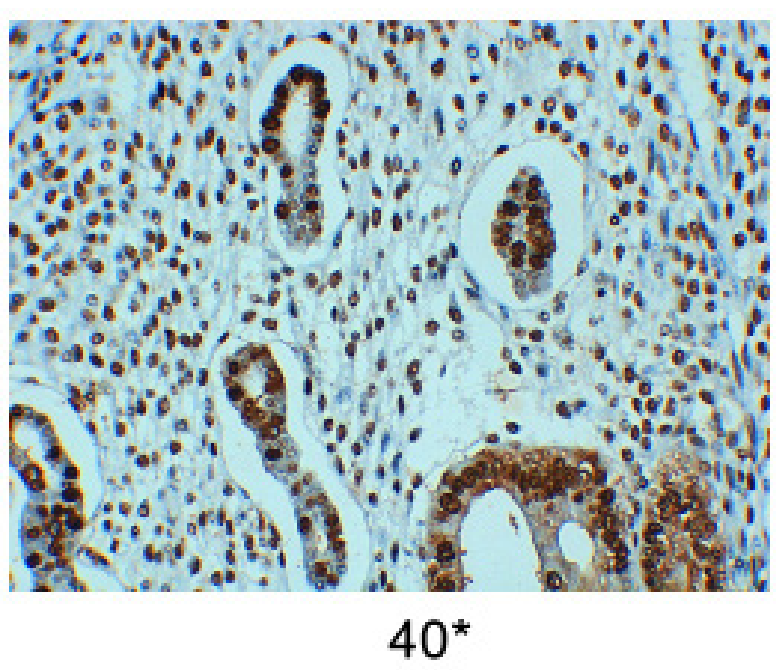

\section{B Low concentration}

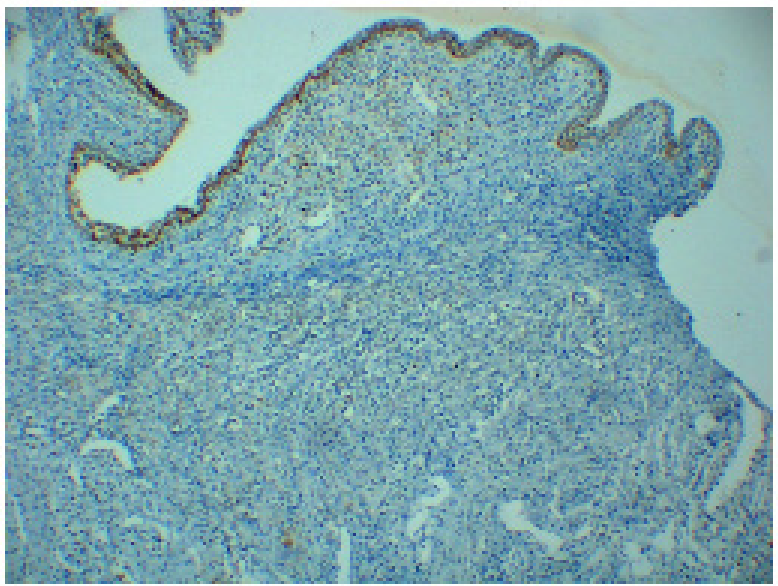

$10^{*}$

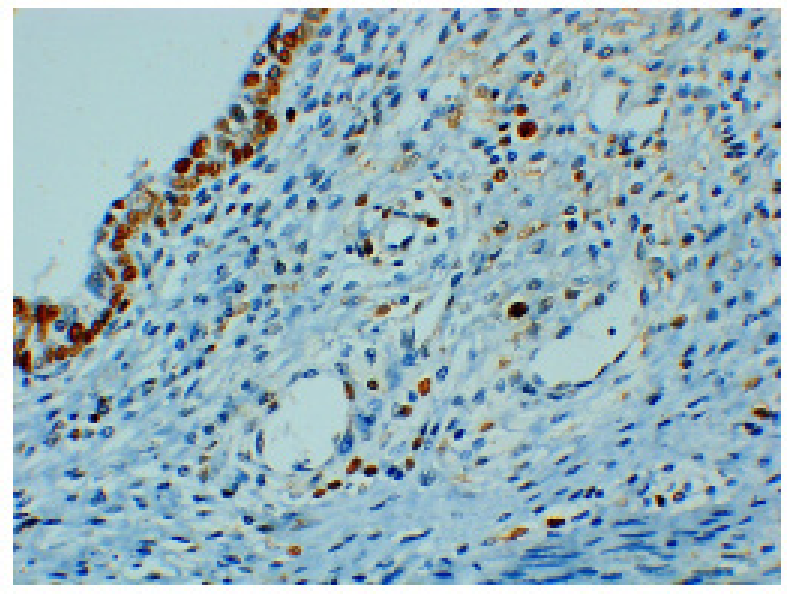

$40 *$

C Medium concentration

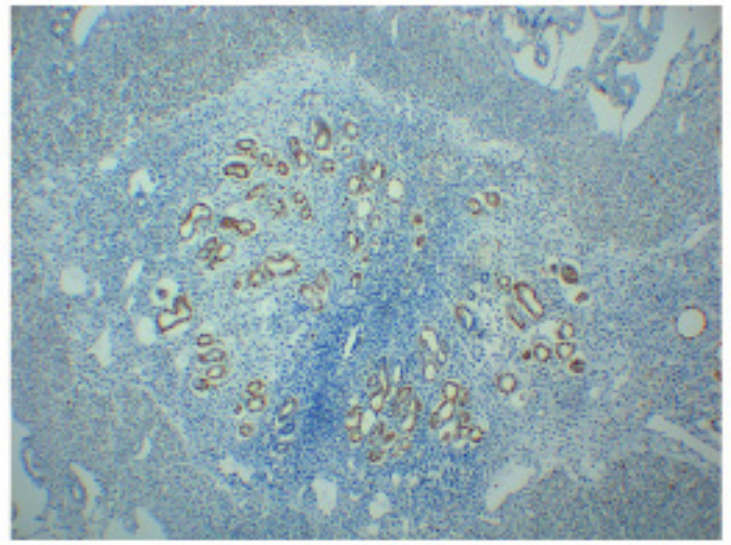

$10 *$

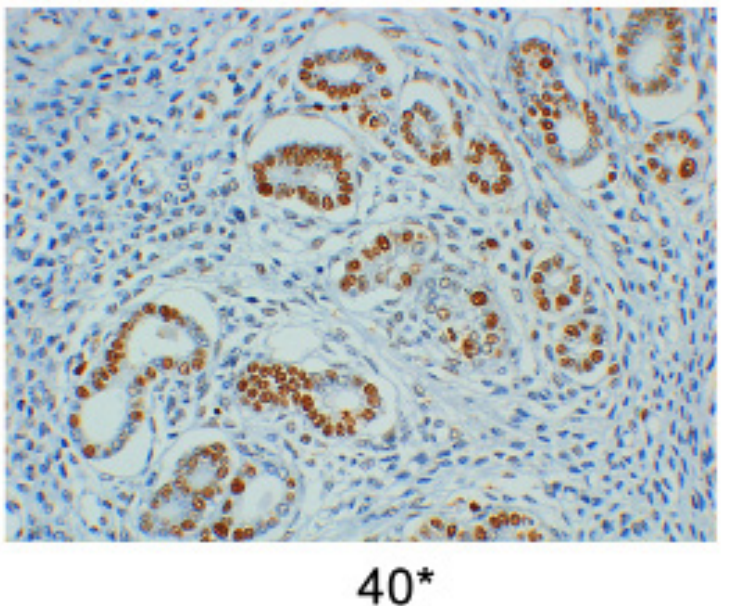

40 *

D High concentration 


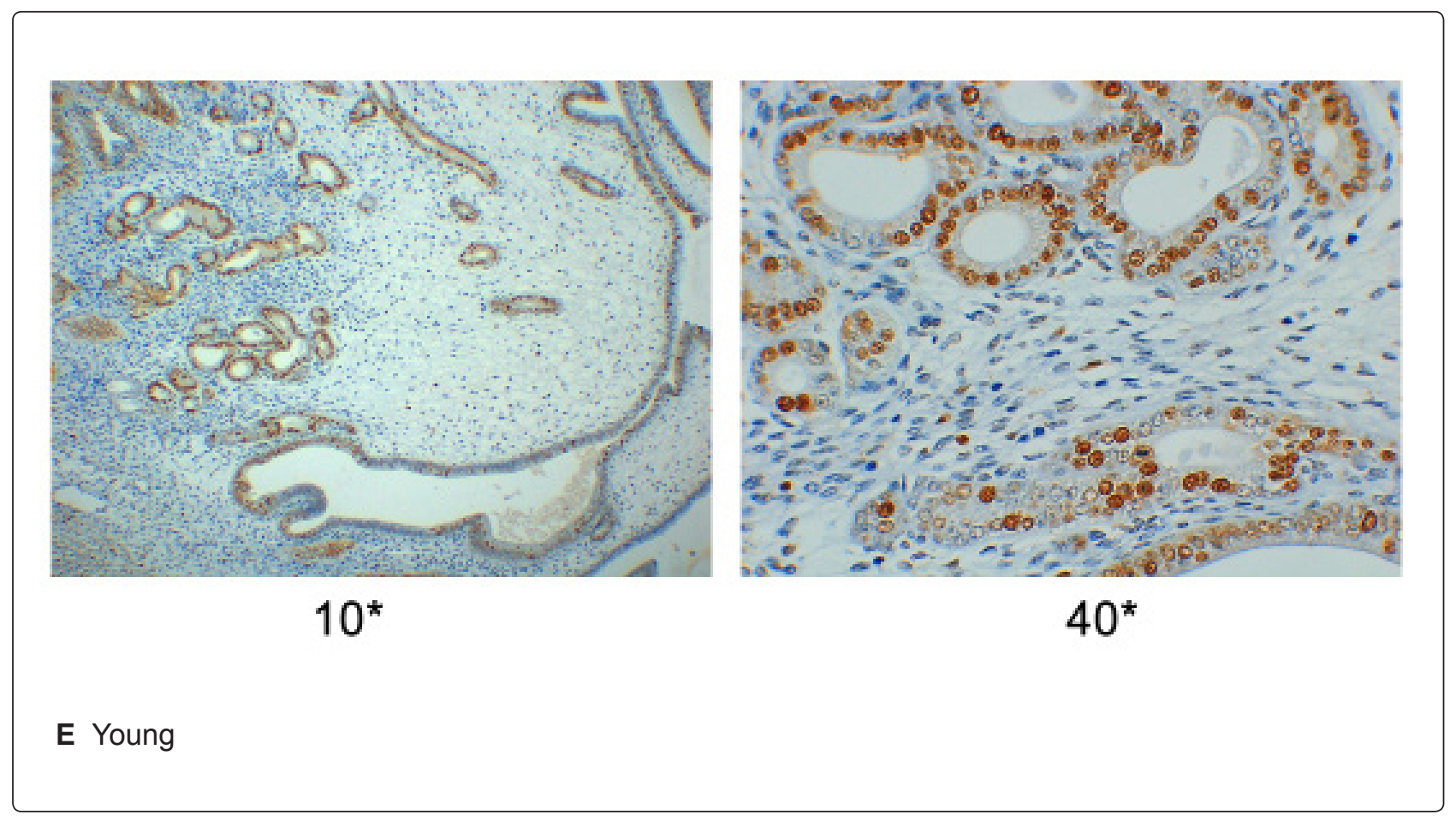

\subsection{LIF Protein Expression by group}

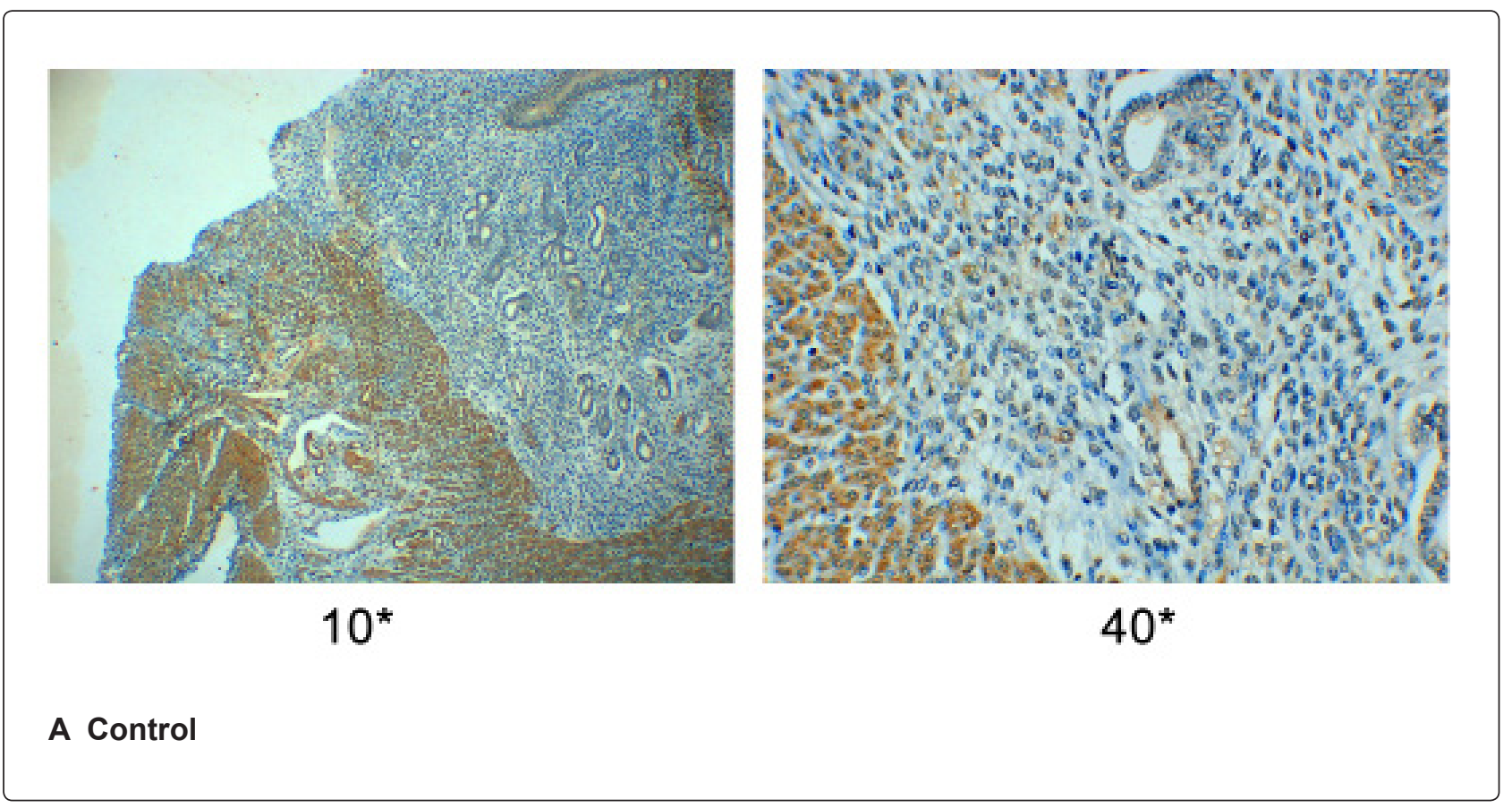




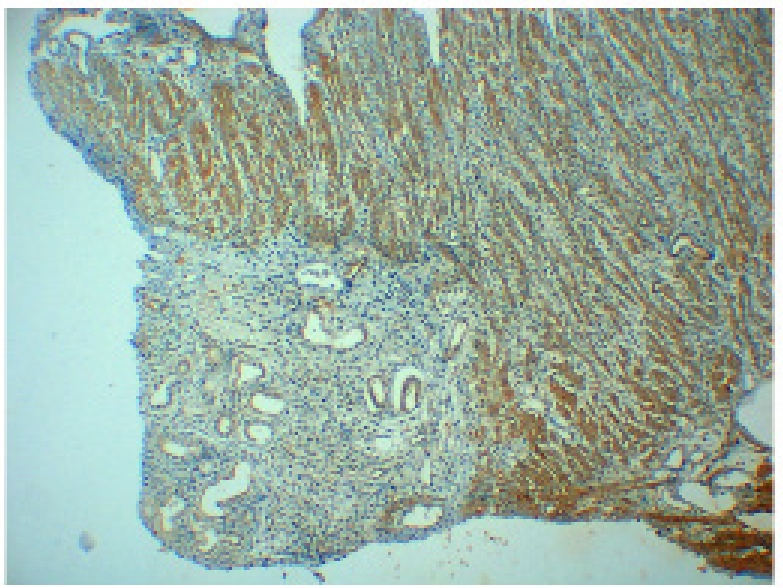

$10^{*}$

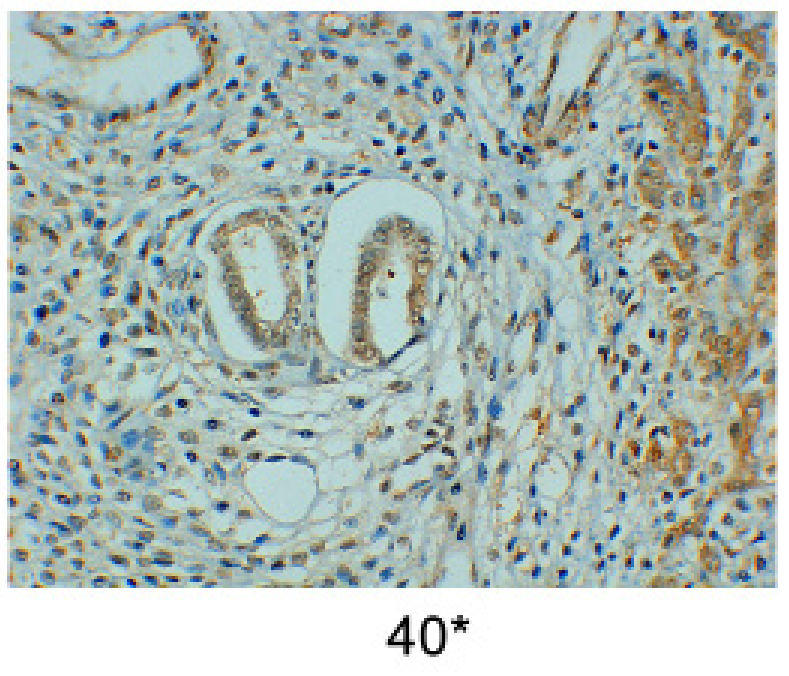

B Low concentration

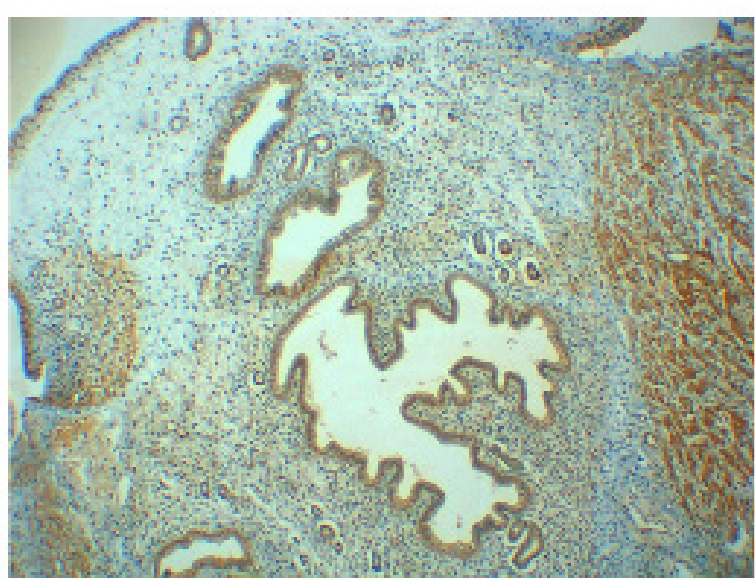

$10^{*}$

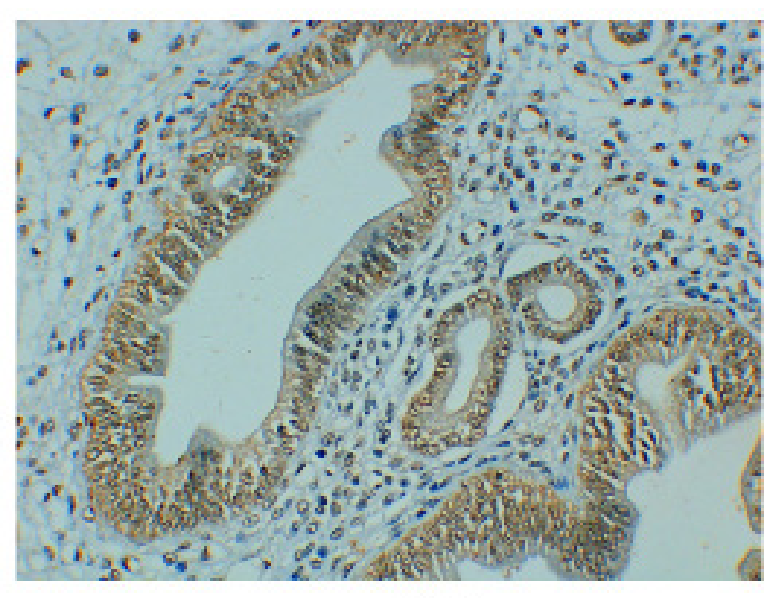

$40 *$

C Medium concentration

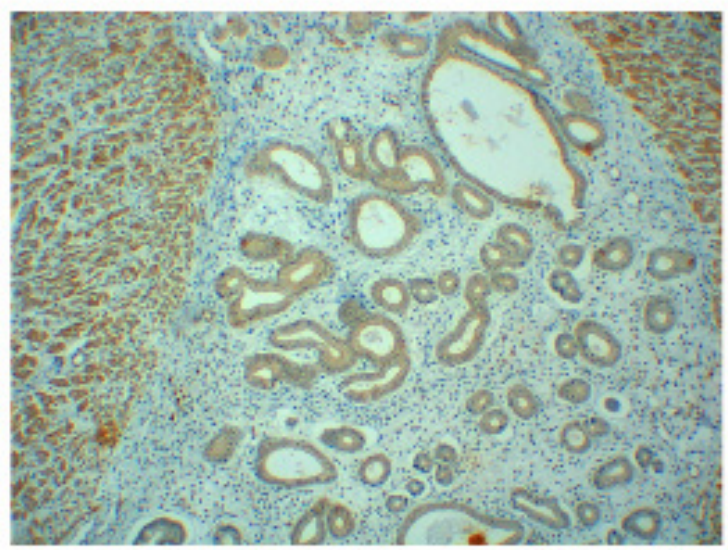

$10^{*}$

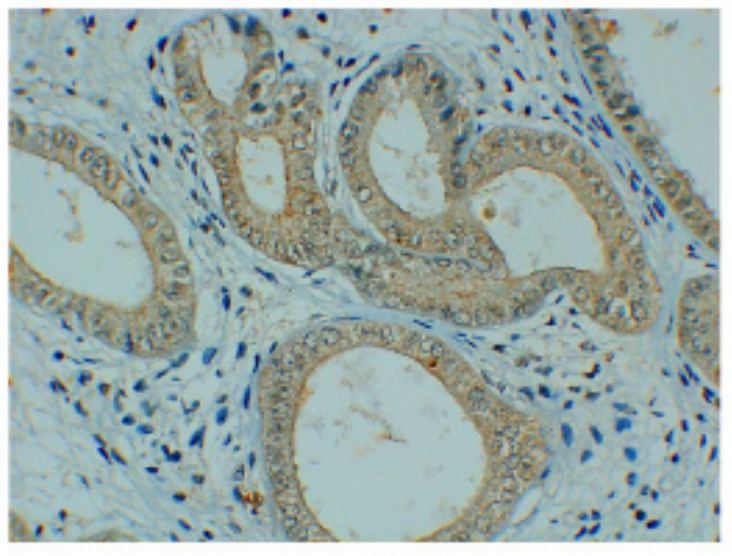

$40 *$

D High concentration 


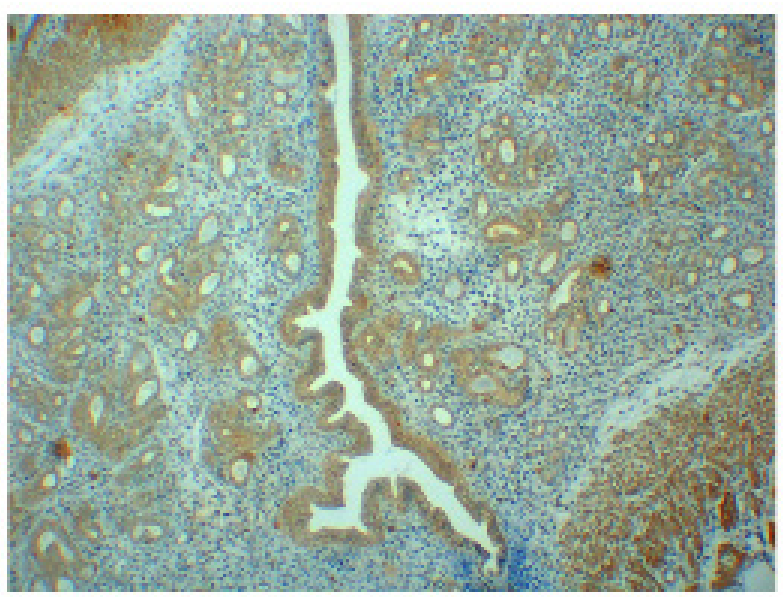

$10^{*}$

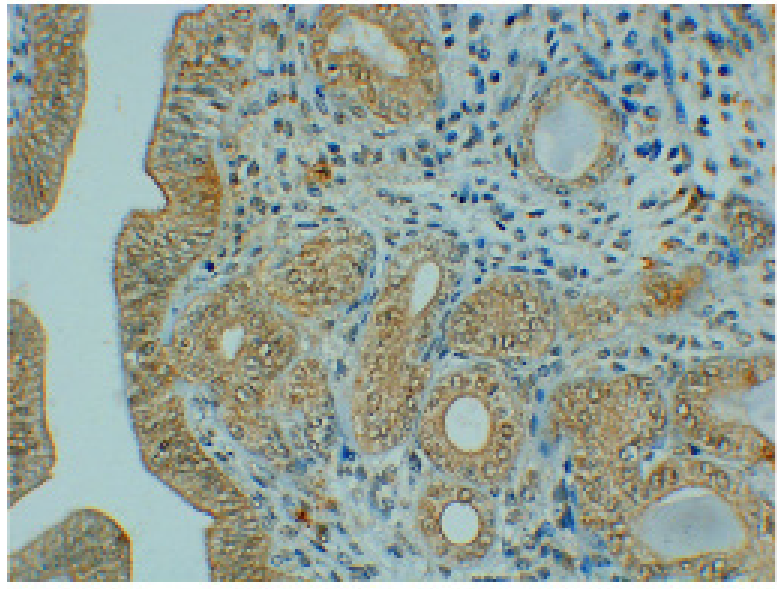

$40^{*}$

E Young

PCNA and LIF protein expressing in adult female mice decreased compared to young female mice.

\section{DISCUSSION}

\subsection{Kuntai capsule effect on menopausal syndrome}

Kuntai capsules contain rehmannia glutinosa, radix rehmanniae, rhizoma coptidis, coptis, radix scutellariae, and poria cocos. The contents nourish Yin to lessen fire, regulate Yin and Yang, and sooth nerves and can relieve restlessness. It can tackle symptoms and improve the menopausal syndrome ${ }^{[4]}$. Some studies ${ }^{[5]}$ show that Kuntai capsules play a two-way regulatory role in hormone level of the menopausal hormonal levels of female mice, and may improve perimenopausal syndrome under conditions of no change of its endogenous hormone level changes.

\subsection{Kuntai capsule effects on PCNA protein expression in perimenopausal female mice}

Recent studies show that PCNA is a marker reflecting cell proliferation activities and plays an important role in DNA replication as an auxiliary protein of DNA polymerase $\delta$. It is an acidic nuclear protein with a molecular weight of $36 \mathrm{KD}^{[6]}$. Jeff $\mathrm{R}$, et al. found that the PCNA gene was subject to up-regulated expression in periimplantation endometriums. It is speculated that PCNA is involved in endometrium proliferation and endometrial decidualization during germ cell adhesion and invasion into the endometrium ${ }^{[7]}$. This study suggests PCNA protein expression in control, and drug, group endometriums was significantly lower than in young group. This indicates that, during perimenopause, PCNA protein expression in the endometrium is affected. After Kuntai capsule administration, PCNA protein expression in mice endometrium increased significantly suggesting that the contents of Kuntai capsules may significantly alleviate negative effects on the perimenopausal endometrium. This effect also increased with Kuntai capsule dosages.

\subsection{Kuntai capsule effects on LIF protein expression in permenopausal female mice}

LIF is a multi-functional cytokine in the interleukin-6 (IL-6) family with many biological functions and has different biological activities in different tissues ${ }^{[8]}$. Recently, studies LIF studies have focused on its role in assisting endometrium development which facilitates embryo implantation ${ }^{[9]}$ which improves the infertile patient pregnancy rates. This study suggests that the expression of LIF proteins expression in the control, and drug, group endometriums was significantly lower than that in the young group. This suggests perimenopause may LIF protein expression in the endometrium. After Kuntai capsule administration, LIF protein expression in mice 
endometrium increased significantly, suggesting that Kuntai capsules may significantly improve the negative effect on perimenopausal endometriums. This improvement also increased with Kuntai capsule dosage increases.

\section{CONCLUSION}

PCNA and LIF protein expression in adult female mice decreased compared to young female mice. The ingredients of Kuntai capsules may significantly improve PCNA and LIF protein expression in female perimenopausal mice. Increased dosages of Kuntain capsules may even more significant improvement.

\section{CONFLICT OF INTEREST STATEMENT}

No conflict of interest and financial disclosure is present. Qiliang Zhou contributed the manuscript, Youru Zhou contributed experimental data and Zhihuo Liu provided language editing services.

\section{FUNDINGS}

This work was supported by a grant from Scientific Research Fund of Hunan Provincial Department of Education (program No.: 15C0158).

\section{REFERENCES}

1. Ivanov PD, Komsa-Penkova RS, Konova EI, Tsvyatkovska TM, Kovacheva KS, Simeonova MN, Tanchev SY. Polymorphism A1/A2 in the cell surface integrin subunit $\beta 3$ and disturbance of implantation and placentation in women with recurrent pregnancy loss. Fertil Steril. 2010; 94 (7): 2843-2845.
2. Peyghambari F, Salehnia M. The correlation between the endome-trial integrins and osteopontin expression with pinopodes development in ovariectomized mice in response to exogenous steroids hormones. Iran Biomed J. 2010; 14(3):109.

3. Dobos G, Tao I. The model of western integrative medicine: the role of Chinese medicine. Chin J Integr Med. 2012; 18(9): 643-651.

4. Chen $R$, Lin SQ, Yang $X$, Luan $Y Q$, Chen JY, Li DM. Effects of Kuntai capsule and estradiol valerate on different symptoms of climacteric syndrome. Med Recapitulate. 2013; 19 (10): 1869-1872.

5. Duan YK, LI F, Li JD, Wei MC, Obstetrics DO. Effects of Kuntai capsule on hormone level and perimenopausal syndrome in the menopausal rats/mice. Chin J Hosp Pharm. 2013; 34 (6): 435.

6. Takahashi H, Strutton GM, Parsons PG. Determination of proliferating fraetions in malig-nant melanomas by anti-PCNA/cyclin monoclonal antibody. Histopathol. 1991; 18(3): 221-227.

7. Ivanov PD, Komsa-Penkova RS, Konova EI, Tsvyatkovska TM, Kovacheva KS, Simeonova MN, Tanchev SY. Polymorphism A1/A2 in the cell surface integrin subunit $\beta 3$ and disturbance of implantation and placentation in women with recurrent pregnancy loss. Fertil Steril. 2010; 94(7): 2843-2845.

8. Takahashi $\mathrm{Y}$, Takahashi M, Carpino N, Jou ST, Chao JR, Tanaka S, Shigeyoshi Y, Parganas $E$, Ihle JN. Leukemia inhitory factor regulates trophoblast giant cell differentiation via Janus Kinasel-Signal Transducer and activator of transcription 3-suppressor of cytokine signaling 3 pathway. Mol Endocrinol. 2008; 22:1673-1681.

9. Peyghambari F, Salehnia M. The correlation between the endome-trial integrins and osteopontin expression with pinopodes development in ovariectomized mice in response to exogenous steroids hormones. Iran Biomed J. 2010; 14(3):109. 